\title{
Apoptotic effect of Atorvastatin in glioblastoma spheroids tumor cultured in fibrin gel.
}

Neda Bayat ${ }^{1}$, Somayeh Ebrahimi-Barough ${ }^{2}$, Abbas Norouzi-Javidan ${ }^{1}$, Hooshang Saberi ${ }^{1}$, Roksana Tajerian $^{2}$, Mohammad Mehdi Mokhtari Ardakan ${ }^{2}$, Sadegh Shirian ${ }^{3}$, Arman Ai ${ }^{4}$, Jafar Ai $^{1,2}$

1- Brain and Spinal Cord Injury Research Center, Neuroscience Institute, Tehran University of Medical Sciences, Tehran, Iran

2- Department of Tissue Engineering and Applied Cell Sciences, Faculty of Advanced Technologies in Medicine, Tehran University of Medical Sciences, Tehran, Iran

3- Department of Pathology, School of Veterinary Medicine, Shahrekord University, Shahrekord, Iran

4- School of Medicine, Tehran University of Medical Sciences, Tehran, Iran

\section{Corresponding author:}

\section{Jafar Ai, Ph.D}

Brain and Spinal Cord Injury Research Center, Neuroscience Institute, Tehran University of Medical Sciences, Tehran, Iran

Tel: +982143052000-110

E-mail: jafar_ai@tums.ac.ir

Somayeh Ebrahimi-Barough, Ph.D

Department of Tissue Engineering and Applied Cell Sciences, Faculty of Advanced Technologies in Medicine, Tehran University of Medical Sciences, Tehran, Iran

Tel: +982143052000-113

E-mail: ebrahimi_s@sina.tums.ac.ir

(C) 2016. This manuscript version is made available under the Elsevier user license http://www.elsevier.com/open-access/userlicense/1.0/ 


\begin{abstract}
Objective: Glioblastoma multiform (GBM) is one of the most common and highly aggressive primary brain tumors that thought to be of glial cells origin. The new available therapy for glioblastoma is based on better understanding of molecular malignant progression in this tumor. It is better to identify key molecular targets stimulating signaling pathways that lead to initiation of apoptosis for treatment of glioblastoma. Tumorigenesis broadly is controlled by tumor microenvironment and design of best biomimetic culture systems dependency on these conditions allow for in vitro and in vivo tumor modeling for studies of cancer cells behavior to drugs. We engineered threedimensional (3D) human tumor models using U87 glioma cells in fibrin gel that mimic microenvironmental feature of glioblastoma in vivo. In this study, atorvastatin was used as a kind of statins for induction of apoptosis, and inhibition of migration and invasion in glioma cells.
\end{abstract}

Methods: To reach for these aims, 3D model of glioma in fibrin gel was used with different concentrations of atorvastatin $(1,5,10 \mu \mathrm{M})$ to assay apoptotic genes expression by real time PCR and Tunel assay. After 24 and 48 hours exposing with different concentrations of atorvastatin, cell migration and invasion of tumor cells were investigated.

Results: The results showed atorvastatin induced apoptosis of glioma spheroids dosedependently. The most likely mechanisms are the induction of apoptosis by caspase-8caspase-3 signaling pathway. The invasion and migration of U87 spheroid cells decreased after 48 hours especially with $10 \mu \mathrm{M}$ concentration of atorvastatin.

Conclusion: Finally these results suggest that this biomimetic model with fibrin may provide a vastly applicable 3D culture system to study the effect of anti-cancer drugs such as atrovastatin on tumor malignancy in vitro and in vivo and atorvastatin could be used as anticancer agent for glioblastoma treatment.

Keywords: Fibrin gel, three dimensional culture, Apoptosis, Glioblastoma, Atorvastatin 


\section{Introduction}

Glioblastoma is highly aggressive brain tumor thought to be of glial, that is astrocytic or oligodendrocytic origin [1]. Glioblastoma multiforme (GBM), a high-grade glioma (WHO grade IV) with an incidence rate of 3.2 per 100,000 is the most common primary brain tumor among adults $[2,3]$. Treatment of malignant glioma is extremely difficult and its prognosis remains very poor and survival time is not more than 12-15 months [2, 4]. New available therapies for dingy prognosis of glioblastomas are treatments based on a better understanding of the molecular malignant progression in this tumor $[2,4,5]$. In the last decades a lot of efforts have been made to analyze the modifications in the molecular pathways of apoptosis in glioblastoma cells to be sensitive towards therapyinduced apoptosis [6]. In pathological and physiological conditions, programmed cell death (apoptosis) plays an important role in cell proliferation [5]. Several mechanisms in glioblastoma cells are blocked like mechanisms for apoptosis or autophagy induction, while several mechanisms are overexpressed like molecular chaperones promoting cell survival [7]. Loss of polarity and detachment of cells from the natural basement membrane in cancer is a big problem, these conditions lead to form distinct threedimensional (3D) structures of cells that interact with each other and with the surrounding microenvironment. There is more evidence that the tumor microenvironment has a critical role in the response of cancer cells to therapeutic agents. For drug testing analysis, the complex 3D extra cellular matrix network structures are critical factor but obtained results from 2D cannot be translated similarly into in vivo settings [8]. The design of 3D tissue culture is necessary to facilitate the development of new in-vitro tumor model assays. One way for study of biopharmaceutical drug discovery on cancers is culture of created spheroid cells in 3D culture systems $[9,10]$. For the development of advanced tissue engineering-based therapies would be helpful techniques that reproduce these 3D cell and tissue patterns in vitro. According to Sutherland et al. studies, 3D spheroid model is the best characterized and most widely used seems to predict in vivo and potentially clinical efficacy better than 2D models [11, 12]. There are several methods have been used to generate tumor spheroids such as spontaneous aggregation, hanging drops, liquid overlay on agar, low binding plates, gel/matrix-based culture, polymeric scaffolds or micropatterned plates [9]. The hanging drop technique was used to 
create embryoid bodies and more recently cancer spheroids encapsulated in fibrin gel [13, 14]. In cancer research, an in vitro tumor model is an essential tool for the assessment of therapeutic drug efficiency prior to in vivo studies. In several experimental systems antiproliferative and apoptotic effects of statins have been observed $[15,16]$.

The statin family of drugs is widely used in the treatment of hypercholesterolemia [17]. They act as competitive inhibitors of 3-hydroxy-3-methylglutaryl-coenzyme A (HMG$\mathrm{CoA}$ ) reductase [17]. There are six members of statin family including lovastatin, simvastatin, atorvastatin, cerivastatin, pravastatin and fluvastatin. The pravastatin and fluvastatin are hydrophilic, whereas the others are lipid soluble [18]. The effects of statins on the molecular mechanisms responsible for apoptosis and inhibition of proliferation are not well understood and the molecular mechanisms that activated by statins have remained unclear. Increasing evidence suggest that statins through their interactions with essential cellular functions, such as cell proliferation and differentiation, might be useful for cancer prevention and/or treatment [18]. Both in vitro and in vivo tumor cells studies have shown that they inhibit tumor growth and induce apoptosis such as melanoma [19], glioma [20], neuroblastoma [21], and leukemia cell lines [22]. Additionally, antitumor activity of statins have also assessed in the several clinical trials [18, 23]. Proposed mechanisms for statin-mediated apoptosis include decreased anti-apoptotic protein expression (e.g., Bcl-2) with upregulation of proapoptotic protein expression (e.g., Bax, Bim) $[18,22,24,26]$. Statins have also been shown to activate caspase proteases involved in programmed cell death. Studies show that statins cause cell death in tumor cells by activating caspase-3, caspase- 8 , and caspase- 9 [18, 27, 29]. To survey the signal transduction mechanisms induced by statins in U87 glioma cells, we have chosen a lipid soluble statin, atorvastatin, because it has been shown that cell death were not able to induce by hydrophilic statins, whereas all hydrophobic ones were associated with apoptosis in endothelial cells [15, 28]. The main purpose of this study was to assess the apoptotic effect of atrovastatin on a glioblastoma cell line (U87) spheroids cultured in fibrin gel as 3D modeling of glioblastoma. In this study, we tested the effects of different concentrations of atrovastatin on migration, proliferation, invasion, and level of apoptosis-related genes in U87 glioblastoma cells spheroids cultured in fibrin gel. 


\section{Materials and Methods}

\subsection{Cell culture}

The U87 human primary glioblastoma cell line was obtained from the Cell Bank of the Pasteur Institute, Tehran, Iran. These cells were all grown and maintained in Dulbecco's modified Eagle's medium (DMEM/F12) containing 10\% fetal bovine serum and 1\% penicillin-streptomycin (complete medium) in a humidified atmosphere of 5\% $\mathrm{CO} 2$.

\subsection{Spheroid formation and Three-Dimensional cell culture in fibrin gel}

In this study we used fibrin gel as hydrogel scaffold for encapsulation of U87 spheroid cells. For glioma spheroids formation, the U87 cell line were cultured in non-adherent plate. Briefly, the cells were washed with PBS, added cell dissociation enzyme and incubated at $37{ }^{\circ} \mathrm{C}$ for $2-5 \mathrm{~min}$ after that cell suspension was centrifuged and removed supernatant and cell pellet re-suspended in $1 \mathrm{ml}$ of complete growth medium. The cell suspension was transferred to a sterile non-adherent 8 -well plate and incubated at $37^{\circ} \mathrm{C}$, $5 \% \mathrm{CO} 2,95 \%$ humidity. Tumor spheroid formation was confirmed visually four days later, and after that glioma spheroids cultured in fibrin gel. To prepare the fibrin gel, $3 \mathrm{mg}$ of fibrinogen (Sigma, USA) was dissolved in $1 \mathrm{ml} \mathrm{M} 199$ solution (Sigma, USA) and along with spheroids transferred to a 24 -well culture dish. Afterward, $15 \mu$ of a thrombin solution (120 U/ml in $1 \mathrm{M}$ sodium buffer; Sigma, USA) and $50 \mu \mathrm{l}$ of fetal bovine serum were added to each well. The culture plates were placed at $37^{\circ} \mathrm{C}$ for $1 \mathrm{~h}$ to form a 3D network structure.

\subsection{Atorvastatin preparation and cell treatment}

Atorvastatin ([R-( $\left.\mathrm{R}^{*}, \mathrm{R}^{*}\right)$-2-(4-Fluorophenyl)- $\beta, \delta$-dihydroxy-5-(1-methylethyl)-3-Phenyl4-(Phenylamino)-Carbonyl]-1-H-Pyrrole-1-heptanoic acid) was purchased from Sigma (USA). It was dissolved in DMSO and filtered through syringe filters $0.22 \mu \mathrm{m}$ for the stock solution of $10 \mathrm{mM}$ and then diluted to $1 \mu \mathrm{M}, 5 \mu \mathrm{M}$ and $10 \mu \mathrm{M}$ concentration with cell culture medium immediately before use. Spheroid U87 encapsulated cells in fibrin gel 
were incubated overnight at at $37{ }^{\circ} \mathrm{C}$. After $24 \mathrm{~h}$ incubation, spheroid cells were treated with 1,5 and $10 \mu \mathrm{M}$ atorvastatin.

\subsection{MTT Cell Growth Assay}

After 48h cell exposing with atorvastatin, the MTT (3-(4,5-Diamethylthiazol-2-yl)-2,5diphenyltetrazolium bromide) assay was used to detecte of cell viability. Encapsulated glioma spheroids in fibrin gel were exposed with different concentrations of atorvastatin $(1 \mu \mathrm{M}, 5 \mu \mathrm{M}$ and $10 \mu \mathrm{M})$ in triplicate wells. After a $48 \mathrm{~h}$ treatment, the medium was removed and the cells were incubated with MTT solution ( $0.5 \mathrm{mg} / \mathrm{ml}$ in PBS; Sigma) for $4 \mathrm{~h}$ at $37^{\circ} \mathrm{C}$. Then, the MTT solution was removed; the formazan crystals were dissolved in DMSO for 15 minutes. The dissolved media from each well were transferred to 96well plate and final absorbance was measured at $570 \mathrm{~nm}$, with spectrophotometric plate reader (Expert 96, Asys Hitch, Ec Austria).

\subsection{Apoptosis assay}

To detect apoptosis of treated tumor cells, terminal deoxynucleotidyl transferasemediated dUTP nick-end labeling (TUNEL) assay was performed by using an in situ cell death detection kit (Roche, Mannheim, Germany) according to the manufacturer instructions at $48 \mathrm{~h}$ post treatment. Glioblastoma spheroid cells cell line (U87) were encapsulated with fibrin gel in 96-well culture plate and treated with atorvastatin at three concentrations of $1 \mu \mathrm{M}, 5 \mu \mathrm{M}$ and $10 \mu \mathrm{M}$. Briefly, cells were harvested, washed and fixed in $4 \%(\mathrm{w} / \mathrm{v})$ paraformaldehyde and were then washed in PBS, and stored in $70 \%$ ethanol at $4{ }^{\circ} \mathrm{C}$ overnight. After being washed with $10 \mathrm{mM}$ Tris- $\mathrm{HCl}(\mathrm{pH}$ 7.6), the cells were incubated in methanol containing $0.3 \% \mathrm{H} 2 \mathrm{O} 2$ for 10 min to quench endogenous peroxidase activity. These cells were then treated with proteinase $\mathrm{K}$ (Roche, $20 \mu \mathrm{g} / \mathrm{ml}$ in Tris buffer) at $37{ }^{\circ} \mathrm{C}$ for $30 \mathrm{~min}$. The cells were then incubated in TUNEL reaction mixture $(450 \mu 1$ of label solution and $50 \mu \mathrm{l}$ of enzyme solution) at $37^{\circ} \mathrm{C}$ for $60 \mathrm{~min}$ and then in horseradish peroxidase (Santa Cruz, Germany) solution for $30 \mathrm{~min}$. The color reaction was developed in 3,30-diaminobenzidine ( $\mathrm{DAB}$, Roche) for 5-10 min. With this procedure, apoptotic cells nuclei will be dark brown. The stained cells were observed under a light microscope (Olympus, Tokyo, Japan). Apoptotic cells were counted in each four groups. 


\subsection{Cell migration assays}

We determined migration ability by a wound-scraping assay. When the cells reached a $90 \%$ confluence with culture medium containing DMEM/F12 with $10 \%$ FBS, the cells were treated with different concentrations of atorvastatin. After $8 \mathrm{~h}$ of treatment, a scratch in the cell monolayer was created by a glass Pasteur pipette tip. The pictures were taken at 0 and $24 \mathrm{~h}$ and $48 \mathrm{~h}$ after making the scratch by using an inverted light microscope (Nikon Eclipse TE2000-S, Germany). The photographs were correlated and the number of cells migrated into the scratch were counted for quantitative analysis.

\subsection{Cell invasion assays}

The 24-well transwell units with a polycarbonate filter ( 8 - $\mu \mathrm{m}$ pore size, Millipore) were used for performing cell invasion assay. These wells were coated on the upper side with $0.1 \mathrm{ml}$ of fibrin. Each lower chamber contained DMEM/F12 supplemented 10\% FBS as the chemoattractant. U87 cells $\left(2 \times 10^{4}\right.$ cell/insert $)$ were seeded into the upper each chamber and treated with different concentrations of atorvastatin then incubated for $48 \mathrm{~h}$. The invasive cells into the lower chambers were fixed in $4 \%$ paraformaldehyde at room temperature for $20 \mathrm{~min}$ and the cells stained with crystal violet for 5 minutes. The invading cells were then rinsed with PBS and were counted under a light microscopy (magnification, $\times 100)$.

\subsection{Quantitative real-time polymerase chain reaction}

After $48 \mathrm{~h}$ exposing with different concentrations of atorvastatin $(1,5$ and $10 \mu \mathrm{M})$, the expression of cell apoptosis markers (Table1) was investigated by real time-PCR. Quantitative real-time PCR was executed using the kit according to the manufacturer's instructions and the ABI7500 Prism Sequence Detection system (Applied Biosystems). The total RNA was extracted from U87 glioma spheroids using RNeasy Plus Mini kit (Qiagen, USA, 74134) and cells were treated with DNase I, RNase-free kit. The synthesis of CDNA was done by a first strand cDNA Synthesis Kit for RT-qPCR (Takara, Gapan). 
In each PCR reaction, 1× Power SYBRH Green PCR Master Mix (ABI PRISM, 4368702) was mixed with 10ng cDNA and specific primers in a total volume of $20 \mu \mathrm{l}$. The comparative $\mathrm{Ct}$ method, $2^{-\mathrm{DDCt}}$, was used for relative gene expression analysis. In each experiment, there were at least three different samples. for each stage, and these were done in duplicates. The primers were designed using Primer 3 software and synthesized by Takara Biotechnology, and are listed in Table 1.

\subsection{Statistical analysis}

Data was presented as means \pm standard deviation (SD.), one-way analysis of variance (ANOVA) was used to analyze differences between treatments and control groups and a p-value $<0.05$ was considered as significant.

\section{Results}

\subsection{Cell growth assay in different concentrations of atorvastatin}

To characterize the effects of atorvastatin on cell proliferation in glioblastomas, we performed dose-response studies in U87 cell line by spheroid form that encapsulated in fibrin gel, spheroids were treated with increasing concentrations of atorvastatin (1, 5 and $10 \mu \mathrm{M}$ ) for $48 \mathrm{~h}$. Atorvastatin markedly inhibited proliferation of U87 cells in a dosedependent manner. These results show that proliferation and survival were reduced for U87 cells exposed to $10 \mu \mathrm{M}$ concentration (Fig. 1A). We found that atorvastatin obviously reduced spheroid size and pseudopodia following 48h incubation (Fig. 1A). These results indicated the potential apoptosis inducing effect of atorvastatin in U87 cells for further analysis. The viability of U87 cells was measured by MTT assay in increasing doses of atorvastatin $(1,5$ and $10 \mu \mathrm{M})$ after $48 \mathrm{~h}$. We found that atorvastatin significantly reduced the viability of U87 cells in a dose dependent manner (Fig. 2).

\subsection{The effect of atorvastatin on glioma spheroids apoptosis by TUNEL assay}

Apoptosis in glioblastoma was detected by in situ end-labeling of nuclear DNA fragments (TUNEL) staining. To determine the apoptotic effect of atorvastatin on U87 cells, cellular spheroids of glioblastoma cells were treated with $1 \mu \mathrm{M}, 5 \mu \mathrm{M}$ and $10 \mu \mathrm{M}$ of atovastatin for $48 \mathrm{~h}$. TUNEL assay analysis of treated glioma spheroids confirmed the 
increased apoptosis in the treated groups, especially at $10 \mu \mathrm{M}$ of atorvastatin than the other treated groups (Fig. 1B, C).

\subsection{Reduction in migration ability of glioma cells with scratch wound healing assay}

The effect of atorvastatin on glioma migration was measured by average cell migration number to the scratch area. When the glioma cells had been incubated by atorvastatin, we observed a significant decrease of migrating cells number as compared to the control group, while the addition of atorvastatin significantly blocked this increase (Fig. 3A). Atorvastatin $10 \mu \mathrm{M}$ slightly reduced migration to the scratch area compared to the other treated groups and control group (Fig. 3B). These data indicated that atorvastatin slightly reduced the migration capacity of U87 cells.

\subsection{Reduction in invasive ability of glioma cells line in the transwell assay}

To determine whether atorvastatin weakens the cell invasion potential, transwell were used by counting the cells invading through the fibrin. The results showed that the cell numbers in the following groups $(1,5,10 \mu \mathrm{M})$ treated with atorvastatin for $48 \mathrm{~h}$ were significantly decreased versus control cells following a dose-dependent manner (Fig. 3C). The average number of invasive cells more decreased by $10 \mu \mathrm{M}$ concentration of atorvastatin compared to the $1 \mu \mathrm{M}$ and $5 \mu \mathrm{M}$-treated groups and control group (Fig. 3D). Clearly, atorvastatin reduced the invasive capacity of the glioma cells significantly.

\subsection{Atorvastatin led to apoptosis-related gene expression in glioma cells}

To understand the molecular mechanism by which atorvastatin regulates apoptosis, we examined the expression of apoptotic factors such as caspase- 3 and caspase- 8 and antiapoptotic protein expression like Bcl-2 on glioma spheroids that affected by atorvastatin. Real-time PCR analysis showed that the expression of caspase- 3 and caspase- 8 at the mRNA level was obviously higher in the treated groups with $10 \mu \mathrm{M}$ than levels in the other treated groups and the expression of Bcl-2 in the treated groups with $10 \mu \mathrm{M}$ was lower than the other groups (Fig. 4). These results suggested that atorvastatin induced cell apoptosis by down-regulating the expression of $\mathrm{Bcl}-2$ and up-regulating the expression of caspase- 3 and caspase- 8 . 


\section{Discussion}

In this study we designed three dimentional culture system for glioblastoma using with U87 spheroids and fibrin gel. This method is good for analysis of drug effects on tumors because can mimic tumor microenvirenment for cancer cells. Promoting tumor cell apoptosis has been recognized as one of the most important methods towards tumor treatment [31]. In the pathogenesis and progression of gliomas, deregulation of the normal mechanism for apoptosis plays an important role [32,33]. Although evidence has accumulated that in regulation of cell apoptosis gene mutations, microRNAs, and growth factors, RNA-binding proteins, DNA-binding transcription factors, $\mathrm{Ca}^{2+}$ binding proteins, signal transduction proteins, and DNA methylation have critical roles [34]. The present study demonstrates the apoptotic potency of atorvastatin [35]. Comparison to nonmalignant cells, statins seems to be more effective in malignant cells to inhibit proliferation and to induce apoptosis [36]. Recent studies have shown that statins reductase inhibitors in several cancers including glioma reduce cell migration and invasiveness [37, 38]. Statins have biphasic potential either to promote or inhibit angiogenesis. Low statin doses induce a proangiogenic effect through the serinethreonine protein kinase Akt activation and increase nitric oxide production, whereas high statin doses may decrease protein prenylation and inhibit cell growth. Xu et al., has shown the effect of different concentration of atorvastatin on smooth muscle cells apoptosis, and the results showed that the $10 \mu \mathrm{M}$ concentrations of atorvastatin had apoptotic effect on this cells. The aim of the present study was to determine the potential inhibitory effect of atorvastatin on glioblastoma proliferation and induction of apoptosis in a three-dimensional fibrin matrix culture of glioma spheroids in vitro, so we chosen 1, 5 and $10 \mu \mathrm{M}$ concentrations of atorvastatin [39, 40]. As before study, we found that atorvastatin reduced glioma cell migration and invasion by suppressing the protumorigenic effects on glioma cells at 1,5 and $10 \mu \mathrm{M}$ concentration. Three dimensional systems have ability to mimic tumor-like microenvironment and this suggests the potential of engineered tumor models for drug testing [28]. The choice of matrix is a major area of contention in 3D culture generation. As outlined earlier, the three most commonly used matrices are basement membrane type gels (Matrigel), collagen I and fibrin [9]. The present study developed simple in vitro cell model that can also be applied 
to evaluate the effect of atorvastatin on glioma cell line. We showed that the glioma model could be used in cancer stem cell research. From the results obtained, we can observe some interesting effects caused by atorvastatin on glioma cells by providing some information on the molecular mechanisms of atorvastatin inhibitory effects. The researchers also demonstrated that atorvastatin resulting in a decrease in osteosarcoma cell invasion blocked the RhoA-JNK-c-Jun-MMP2 cascade [41]. We confirmed recent data that statins suppress migration, invasion, and proliferation of glioma cell lines [36, 42], and also induced apoptosis and cell death [36, 43]. In agreement with the previous reports, our data show that numbers of TUNEL positive cells are significantly increased in atorvastatin groups. Also, recent findings have shown that atorvastatin has anti-tumor effect in several cancers including osteosarcoma and non-small-cell-lung carcinomas (NSCLCs) [37, 44]. The anti-tumor effects may include cytotoxicity [45], induction of apoptosis [46] and inhibitory effects on matrix metalloproteinases (MMPs) [41]. A common feature of many of studies is that high statin concentrations $(\mu \mathrm{M}$ to $\mathrm{mM}$ amounts) were demanded to cause apoptosis and cell death although there are exceptions $[36,47]$. The results of the MTT assay confirmed that atorvastatin effectively reduced the growth of U87 cells in a dose-dependent manner. Furthermore, at increasing concentrations of atorvastatin, the cells became rounder and, which was the morphological characteristics of apoptosis.

We found that atorvastatin induced apoptosis of U87 cells in an increasing trend, but treatment with $10 \mu \mathrm{M}$ atorvastatin, the percentage of total apoptosis increased more significant compared with the untreated group $(\mathrm{P}>0.001)$. By contrast, the apoptosis rates were identified to be significantly different compared with the control group $(\mathrm{P}<$ 0.05). In addition, certain studies have previously noticed that atorvastatin induced cell apoptosis in different cancer cell lines [48], which is consistent with the results of our study. Effective anti-glioblastoma therapy should not only inhibit tumor cell growth, but also prevent invasion of cancer cells [49]. We also investigated the effects of atorvastatin on the invasion ability of U87 glioblastoma cells. The invasion assay showed that atorvastatin inhibited invasion ability of U87 cells. The results conformed to studies which demonstrated that atorvastatin inhibited invasion in different cancer cell lines [37]. In short, atorvastatin is a potential chemopreventive agent for glioblastoma that can 
inhibit U87 glioblastoma cells apoptosis, migration and invasion, but the molecular mechanisms through which atorvastatin affects glioblastoma cells remain unclear. In order to clarify the exact mechanisms of apoptosis and invasion inhibition effects in U87 glioblastoma cells, we investigated the influence of atorvastatin on the crucial proteins associated with apoptosis, migration and invasion.

We surveyed apoptosis mechanism of atorvastatin on glioblatoma through the comprehensive expression of Bcl-2, caspase-3, and caspase-8. According to the results of the present study, atorvastatin down-regulated the expression of Bcl-2 and up-regulated the expression ofcaspase- 3 and the caspase- 8 , which indicated that these proteins are involved in the atorvastatin triggered apoptosis in U87cells.

Our results showed low protein expression of Bcl-2, providing molecular evidence that the protein Bcl-2 can induce cell death in GBM. Evidence has been demonstrated that caspase is a central executioner of apoptosis machinery, and over-expression and activation of caspases in human cells lead to apoptosis [49-51]. There are two main apoptosis pathways, mitochondrial pathways and death receptor-mediated pathways [52], when caspase- 8 pro-enzyme is activated, it activates caspase- 3 to trigger apoptosis. The two pathways converge at activation of the effector caspases (caspase-3, caspase-7 and caspase-6). It is known that both the death receptor and the mitochondrial pathway can be interconnected via the activation of the pro-apoptotic Bcl-2 family member, Bid, through caspase-8, possibly serving as an amplification loop [46, 53]. However, there is some crosstalk between the pathways; for example, the activated caspase- 8 can also trigger activation of caspase-9 [54]. Caspases are key factors in the execution of apoptosis. In this study, atorvastatin significantly increased caspase-3 mRNA expression observed 48 hour after exposing. It is most likely that atorvastatin induces apoptosis by elevating their upstream signal where cytochrome $\mathrm{C}$ interacts with caspases signaling pathways. In this study, we determined the antitumor activity effects of atorvastatin in glioma spheroid cells in vitro and investigated the subjacent molecular mechanisms responsible for that. The results of this study indicated the usefulness of atorvastatin in efficient control of glioma, but future studies should investigate the effects of atorvastatin in glioma in vitro and in vivo. 


\section{Conclusions}

In summary, the cancer cell spheroid encapsulated in fibrin gel can mimic the microenvirenment of tumors and with this model we can survey the effect of drugs on tumor cells. Atorvastatin has potent apoptosis inducing effect, migration and invasion inhibiting effects against U87 glioblastoma cells, that these effects are dose dependent. This study proposes that atorvastatin may be a suitable candidate for glioblastoma treatment. However, to the best of our knowledge, numerous mechanisms are involved in arovastatin-induced apoptosis, migration and invasion inhibition, further research is required to elucidate these.

\section{Conflict of interest}

No competing financial interests exist.

\section{Acknowledgment}

We thank the Iran National Science Foundation (INSF) for the financial support (grant number 93051217) and Tehran University of Medical Sciences for this research.

\section{References}

1- H. Ohgaki, P. Kleihues, Population-based studies on incidence, survival rates, and genetic alterations in astrocytic and oligodendroglial gliomas, J. Neuropathol Exp Neurol. 64 (2005) 479-489.

2- S. Sathornsumetee, D.A. Reardon, A. Desjardins, J.A. Quinn, J.J. Vredenburgh, J.N. Rich, Molecularly targeted therapy for malignant glioma, cancer.110 (2007) $13-24$.

3- M. Nakada, S. Nakada, T. Demuth, N.L. Tran, D.B. Hoelzinger, M.E. Berens, Molecular targets of glioma invasion, Cell Mol Life Sci. 64 (2007) 458-78. 
4- R. Stupp, W.P. Mason, M.J. van den Bent, M. Weller, B. Fisher, M.J.B. Taphoorn, et al., Radiotherapy plus concomitant and adjuvant temozolomide for glioblastoma, New Engl J Med. 352 (2005) 987-96.

5- A.M. Omuro, S. Faivre, E. Raymond, Lessons learned in the devel- 8. opment of targeted therapy for malignant gliomas. Mol Cancer Ther. 6 (2007) 1909-19.

6- G. Eisele, M. Weller, Targeting apoptosis pathways in glioblastoma, Cancer Letters .332 (2013) 335-345.

7- I.M. Ghobrial, T.E. Witzig, A. Adjei, Targeting apoptosis pathways in cancer therapy, CA Cancer J Clin. 5 (2005) 178-94.

8- X. Xu, M.C. Farach-Carson, X. Jia, Three-dimensional in vitro tumor models for cancer research and drug evaluation, Biotechnol Adv. 32 (2014) 1256-68.

9- M. Vinci, S. Gowan, F. Boxall, L. Patterson, M. Zimmermann, W. Court, C. Lomas, M. Mendiola, D. Hardisson, S. Eccles, Advances in establishment and analysis of three-dimensional tumor spheroid-based functional assays for target validation and drug evaluation, BMC Biology. 10 (2012) 1-20.

10- K.S. Smalley, M. Lioni, K. Noma, N.K. Haass, M. Herlyn, In vitro threedimensional tumor microenvironment models for anticancer drug discovery, Expert Opin Drug Discov. 3 (2008) 1-10.

11- R.M. Sutherland, J.A. McCredie, W.R. Inch, Growth of multicell spheroids in tissue culture as a model of nodular carcinomas, J. Natl Cancer Inst. 46 (1971) 113-120.

12- I.A. Ho, W.H. Ng, P.Y. Lam, FasL and FADD delivery by a glioma-specific and cell cycle-dependent HSV-1 amplicon virus enhanced apoptosis in primary human brain tumors, Mol Cancer .9 (2010) 1-15.

13- C.S. Chen, M. Mrksich, S. Huang, G.M. Whitesides, D.E. Ingber, Geometric control of cell life and death, Science. 276 (1997) 1425-1428. 
14- J. Moll, R. Colombo, Target Identification and Validation in Drug Discovery: Methods and Protocols, Methods in Molecular Biology e Book vol. (2013) 986.

15- M. Koyuturk, M. Ersoz, N. Altiok, Simvastatin induces proliferation inhibition and apoptosis in C6 glioma cells via c-jun N-terminal kinase, Neuroscience Letters. 370 (2004) 212-217.

16- D.Z. Hillyard, A.J. Kameron, A.H. McIntyre, M.H. Hadden, H.E. Marshall, N. Johnston, A.G Jardine, Inhibition of proliferation and signaling mechanisms in human lymphocytes by fluvastatin, Clin Exp Pharmacol Physiol. 29 (2002) 673678.

17- M. Farnier, J. Davignon, Current and future treatment of hyperlipi- demia: the role of statins, Am J Cardiol. 82 (1998) 3J-10J.

18- K. Hindler, C.S. Cleeland, E. Rivera, C.D. Collard, The Role of Statins in Cancer Therapy, The Oncologist. 11 (2006) 306-315.

19- Y.G Shellman., D. Ribble, L. Miller, Lovastatin-induced apoptosis in human melanoma cell lines, Melanoma Res. 15 (2005) 83-89.

20- H.H. Song, K.M. Park, S. Gerecht, Hydrogels to model 3D in vitro microenvironment of tumor vascularization, Adv Drug Deliv Rev. 15 (2014) 1929.

21- R. Girgert, Y. Vogt, D. Becke, G. Bruchelt, P. Schweizer, Growth inhibition of neuroblastoma cells by lovastatin and L-ascorbic acid is based on different mechanisms, Cancer Lett. 137 (1999) 167-172.

22- J. Dimitroulakos, S. Thai, G.H. Wasfy, Lovastatin induces a pronounced differentiation response in acute myeloid leukemias, Leuk Lymphoma. 40 (2000) 167-178.

23- J.J. Knox, L.L. Siu, E. Chen, A phase I trial of prolonged administration of lovastatin in patients with recurrent or metastatic squamous cell carcinoma of the head and neck or of the cervix, Eur J Cancer. 41 (2005) 523-530. 
24- A. Corsini, F.M. Maggi, A.L. Catapano, Pharmacology of competi- tive inhibitors of HMG-CoA reductase, Pharmacol Res. 31 (1995) 9-27.

25- B. Agarwal, S. Bhendwal, B. Halmos, Lovastatin augments apoptosis induced by chemotherapeutic agents in colon cancer cells, Clin Cancer Res. 5 (1999) 22232229.

26- F.E. McDonald, J.W. Ironside, A. Gregor, B. Wyatt, M. Stewart, R. Rye, The prognostic influence of bcl-2 in malignant glioma, Br J Cancer. 86 (2002) 18991904.

27- P. Cafforio, F. Dammacco, A. Gernone, Statins activate the mitochondrial pathway of apoptosis in human lymphoblasts and myeloma cells, Carcinogenesis. 26 (2005) 883-891.

28- S. Kaneta, K. Satoh, S. Kano, M. Kanda, K. Ichihara, All hydrophobic HMG-CoA reductase inhibitors induce apoptotic death in rat pulmonary vein endothelial cells, Atherosclerosis. 170 (2003) 237-243.

29- A. Korshunov, A. Golanov, R. Sycheva, I. Pronin, Prognostic value of tumor associated antigen immunoreactivity and apoptosis in cerebral glioblas- tomas: an analysis of 168 cases, J. Clin Pathol. 52 (1999) 574-580.

30- E.C. Quant, J. Drappatz, P.Y. Wen, A.D. Norden, Recurrent High-Grade Glioma, Current Treatment Options in Neurology. 12 (2010) 321-333.

31- L. Feng, W. Au-Yeung, Y.H. Xu, S.S. Wang, Q. Zhu, P. Xiang, Oleanolic acid from Prunella Vulgaris L. induces SPC-A-1 cell line apoptosis via regulation of Bax, Bad and Bcl-2 expression, Asian Pac J Cancer Prev. 12 (2011) 403-408.

32- C. Hao, F. Beguinot, G. Condorelli, Induction and intracellular regulation of tumor necrosis-related apoptosis-inducing ligand (TRAIL) mediated apoptosis in human malignant glioma cells, Cancer Res. 61(2001) 1162-1170.

33- C.D. Riffkin, A.Z. Gray, C.J. Hawkins, Ex vivo pediatric brain tumors express Fas (CD95) and FasL (CD95L) and are resistant to apoptosis induction, Neuro Oncol. 3 (2001) 229-240. 
34- F.P. Saggioro, L. Neder, J.N. Stávale, A.N. Paixão-Becker, S.M. Malheiros, F.A. Soares, J.E. Pittella, C.C. Matias, B.O. Colli, C.G. Carlotti, M. Franco, Fas, FasL, and cleaved caspases 8 and 3 in glioblastomas: a tissue microarray-based study, Pathol Res Pract. 5 (2014) 267-73.

35- G. Martin, H. Duez, C. Blanquart, V. Berezowski, P. Poulain, J.C. Fruchart, J. Najib-Fruchart, C. Glineur, B. Staels, Statin-induced inhibition of the Rhosignaling pathway activates PPAR $\alpha$ and induces HDL apoA-I, J. Clin InvestJun. 107 (2001) 1423-1432.

36- S. Afshordel, B. Kern, J. Clasohm, H. König, M. Priester, J. Weissenberger, D. Kögel, G.P. Eckert, Lovastatin and perillyl alcohol inhibit glioma cell invasion, migration, and proliferation--impact of Ras-/Rho-prenylation, Pharmacol Res. 91 (2015) 69-77.

37- Y. Yongjun, H. Shuyun, C. Lei, C. Xiangrong, Y. Zhilin, K. Yiquan, Atorvastatin suppresses glioma invasion and migration by reducing microglial MT1-MMP expression, J. Neuroimmunol. 260 (2013) 1-8.

38- T. Murai, Y. Maruyama, K. Mio, H. Nishiyama, M. Suga, C. Sato, Low cholesterol triggers membrane microdomain-dependent CD44 shedding and suppresses tumor cell migration, J. Biol Chem. 286 (2011) 1999-2007.

39- Y.G. Xu, S.H. Zhou, Y.G. Li, C.H. Zheng, X.P. Li, Q.M. Liu, D.M. Xu, S. Chen. The mechanism underlying vascular smooth muscle cell apoptosis induced by atorvastatin may be mainly associated with down-regulation of survivin expression. Cardiovasc. Drugs. Ther. 21(2007):145-153.

40- N. Esfandiari, M. Khazaei, J. Ai, R. Bielecki, L. Gotlieb, E. Ryan, R.F. Casper. Effect of a statin on an in vitro model of endometriosis. Fertil. Steril. 87(2007) $: 257-262$.

41- O. Fromigue, Z. Hamidouche, P.J. Marie, Blockade of the RhoA-JNK-c-JunMMP2 cascade by atorvastatin reduces osteosarcoma cell invasion, J. Biol Chem. 283 (2008) 30549-30556. 
42- H. Wu, H. Jiang, D. Lu, Y. Xiong, C. Qu, D. Zhou, Effect of simvastatin on glioma cell proliferation, migration, and apoptosis, Neurosurgery. 65 (2009) 1087-96.

43- W.G. Wood, U. Igbavboa, W.E. Muller, G.P. Eckert, Statins, Bcl-2, and apoptosis: cell death or cell protection, Mol Neurobiol. 48 (2013) 308-14.

44- J. Chen, J. Hou, J. Zhang, Y. An, X. Zhang, L. Yue, J. Liu, X. Li, Atorvastatin synergizes with IFN-gamma in treating human non-small cell lung carcinomas via potent inhibition of RhoA activity, Eur J. Pharmacol. 682 (2012) 161-170.

45- J.H. Tapia-Perez, E. Kirches, C. Mawrin, R. Firsching, T. Schneider, Cytotoxic effect of different statins and thiazolidinediones on malignant glioma cells, Cancer Chemother Pharmacol. 67 (2011) 1193-1201.

46- Z. He, L.S. Mangala, C.A. Theriot, L.H. Rohde, H. Wu, Y. Zhang, Cell killing and radiosensitizing effects of atorvastatin in PC3 prostate cancer cells, J. Radiat Res. 53 (2012) 225-233.

47- N. Bansal, A.G. Houle, G. Melnykovych, Comparison of dexamethasone and lovas- tatin (mevinolin) as growth inhibitors in cultures of T-cell derived human acute leukemia lines (CEM), Leukemia Res. 13 (1989) 875-82.

48- I. Aprigliano, J. Dudas, G. Ramadori, B. Saile, Atorvastatin induces apoptosis by a caspase-9-dependent pathway: an in vitro study on activated rat hepatic stellate cells, Liver Int. 28 (2008) 546-57.

49- Z. Zhang, C. Li, L. Shang, Y. Zhang, R. Zou, Y. Zhan, B. Bi, Sulforaphane induces apoptosis and inhibits invasion in U251MG glioblastoma cells, Springerplus. 29 (2016) 5:235.

50- X. Xie, H. Zhu, H. Yang, W. Huang, Y. Wu, Y. Wang, Y. Luo, D. Wang, G. Shao, Solamargine triggers hepatoma cell death through apoptosis, Oncol Lett. 10 (2015) 168-174. 
51- J. Yi, X. Yang, L. Zheng, G. Yang, L. Sun, Y. Bao, Y. Wu, Y. Huang, C. Yu, S.N. Yang, Y. Li, Photoactivation of hypericin decreases the viability of RINm5F insulinoma cells through reduction in JNK/ERK phosphorylation and elevation of caspase-9/caspase-3 cleavage and Bax-to-Bcl-2 ratio. Biosci Rep 20 (2015) 1-13.

52- E. Bossy-Wetzel, D.R. Green, Caspases induce cytochrome c release from mitochondria by activating cytosolic factors, J. Biol Chem. 274 (1999) 17484-90.

53- G.A. Ciftci, A. Iscan, M. Kutlu, Escin reduces cell proliferation and induces apoptosis on glioma and lung adenocarcinoma cell lines, Cytotechnology. 67 (2015) 893-904.

54- A. Hoque, H. Chen, X.C. Xu, Statin induces apoptosis and cell growth arrest in prostate cancer cells, Cancer Epidemiol Biomarkers Prev. 17 (2008) 88-94.

\section{Figure captions:}

Fig. 1 Atorvastatin induced apoptosis. (A) Dose dependent effect of atorvastatin on proliferation of glioma spheroid cells. Glioma spheroid cell that encapsulated in fibrin were treated with $1 \mu \mathrm{M}, 5 \mu \mathrm{M}$ and $10 \mu \mathrm{M}$ atorvastatin over a period of $48 \mathrm{~h}$. At the indicated time point spheroids were observed with invert microscope. The proliferation rate was inhibited by all concentration, especially at $10 \mu \mathrm{M}$. (B) Apoptotic index. The TUNEL technique revealed the specific apoptosis-induced DNA strand breaks and provided the percentages of positive cells. Cells were treated with different concentrations of atorvastatin for $48 \mathrm{~h}$. Apoptotic nuclei and fragmented DNA appeared dark brown after staining. (C) Results are expressed as mean $\pm \operatorname{SEM}(\mathrm{n}=3)$. $* * * \mathrm{P}<0.001$ compared with control, error bars indicate SE.

Fig. 2. Effect of atorvastatin on U87 cell viability. U87 cells were treated with $1 \mu \mathrm{M}, 5 \mu \mathrm{M}$ and $10 \mu \mathrm{M}$ atorvastatin for $48 \mathrm{~h}$. The cell viabilities were determined by MTT assay. MTT assay showed that $10 \mu \mathrm{M}$ atorvastatin inhibited proliferation more than other concentrations. Experiments were performed three times in triplicate. Data are presented as mean $\pm \mathrm{SD}$. 
Fig. 3. Effect of atorvastatin on U87 glioblastoma cell line migration and invasion. (A, B) Migration of U87 cells after treatment with atorvastatin $(1 \mu \mathrm{M}, 5 \mu \mathrm{M}$ and $10 \mu \mathrm{M})$ for $48 \mathrm{~h}$. U87 cells were seeded in 6-well plates after 80-90\% concentration scratched with a pipette tip and then incubated with different concentrations of atorvastatin. Photographs were taken of the gaps observed under microscope at $0 \mathrm{~h}, 24 \mathrm{~h}$ and $48 \mathrm{~h}$. (C, D) Invasion of U87 cells after treatment with atorvastatin $(1 \mu \mathrm{M}, 5 \mu \mathrm{M}$ and $10 \mu \mathrm{M})$. U87 cells were incubated for $48 \mathrm{~h}$ in the absence or presence of atorvastatin, and the cells invading the bottom side of the insert membranes were stained with crystal violet and counted under a microscope. Values are the means \pm SEM from three independent determinations. Significance compared with control, $* * * p<0.001$.

Fig. 4. Real time-PCR analysis of the mRNA levels of the pro- apoptotic genes (caspase3 and capase-8) and anti-apoptotic gen Bcl-2 in glioma spheroid cells encapsulated in fibrin gel that treated with atorvastatin in the different concentrations. Presenting data are mean $\pm \mathrm{SD}$ of three identical experiments made in three replicate followed by normalization with GAPDH protein amount. $(* \mathrm{p}<0.05$; ** $\mathrm{p}<0.01$; ***p $<0.001)$.

Table 1. Primers used for real time RT-PCR

\begin{tabular}{lccc}
\hline Gene & Size (bp) $\quad$ primer sequence(5'-3') & annealing $\left({ }^{\circ} \mathrm{C}\right)$ \\
\hline Bcl2 & 156 & F AAAATACAACATCACAGAGGAAGTAGACTG & 59 \\
& & R TCAATCACGCGGAACACTTG & \\
Caspase-3 & 143 & F AAAAGCACTGGAATGACATCTCG & 59 \\
& & R GAAACATCACGCATCAATTCCAC & \\
Caspase-8 & 161 & F ACTGGATGATGACATGAACCTGC & \\
& & R CCTCCCCTTTGCTGAATTCTTC & 59 \\
GAPDH & 215 & F TCGCCAGCCGAGCCA &
\end{tabular}


Control
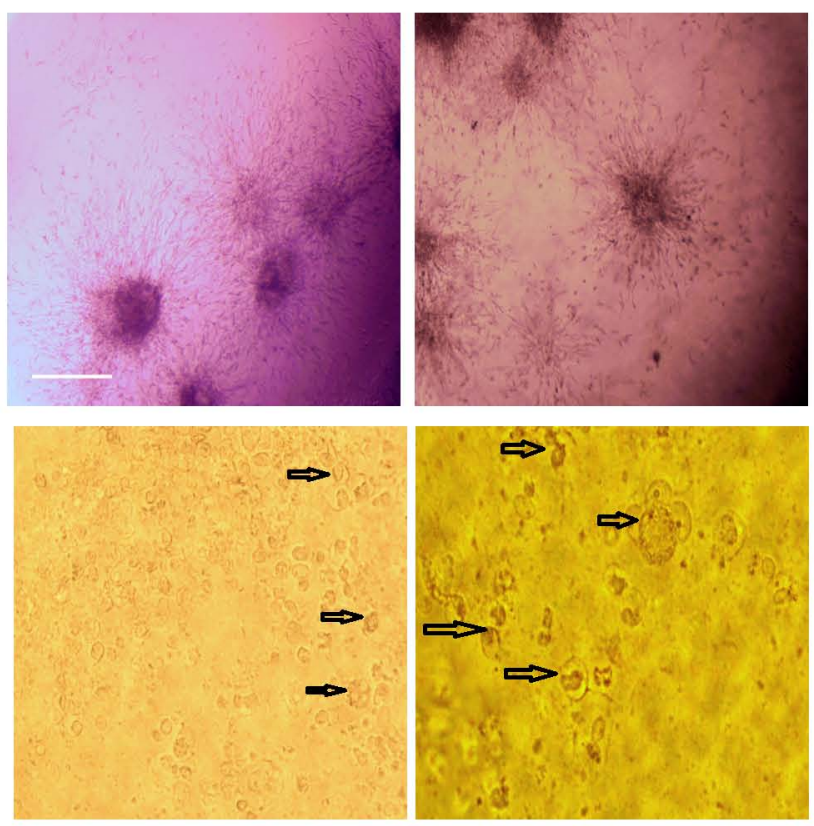

$5 \mu \mathrm{M}$
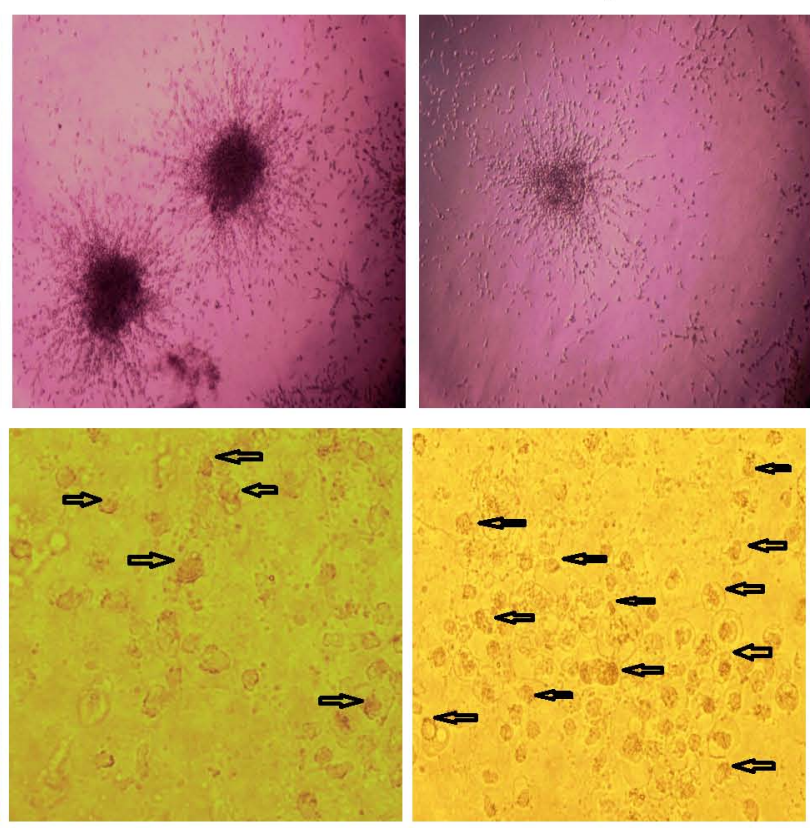

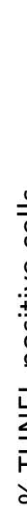

TUNEL

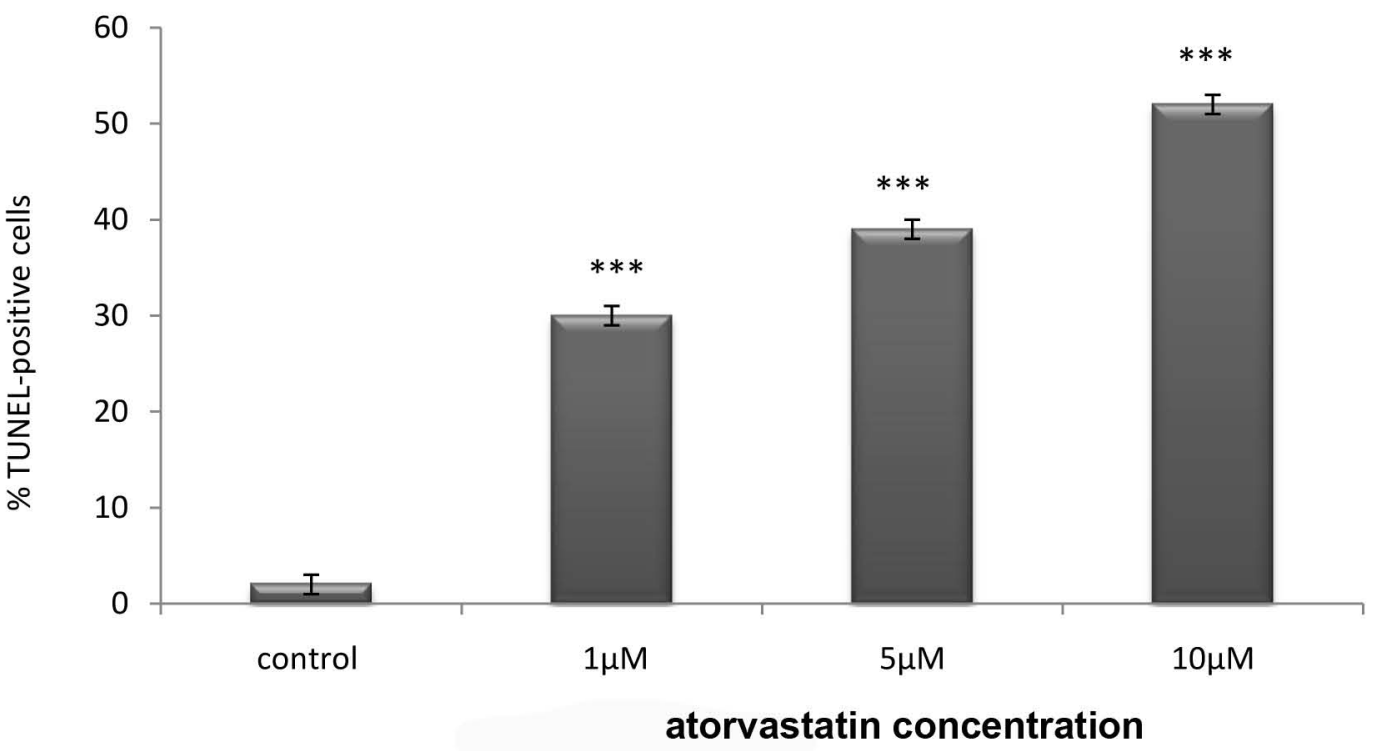




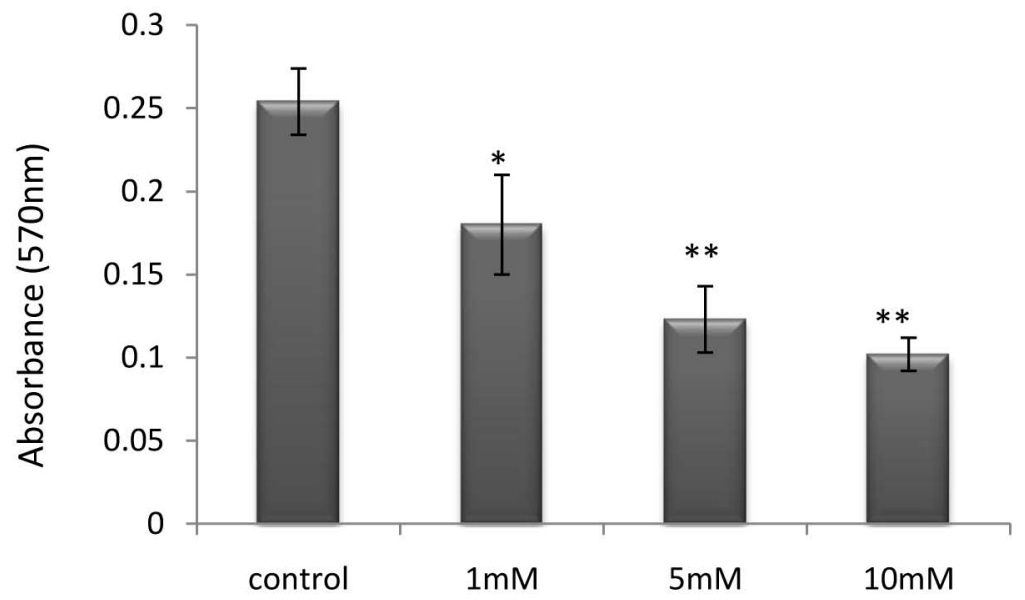

口48h 


\section{A}

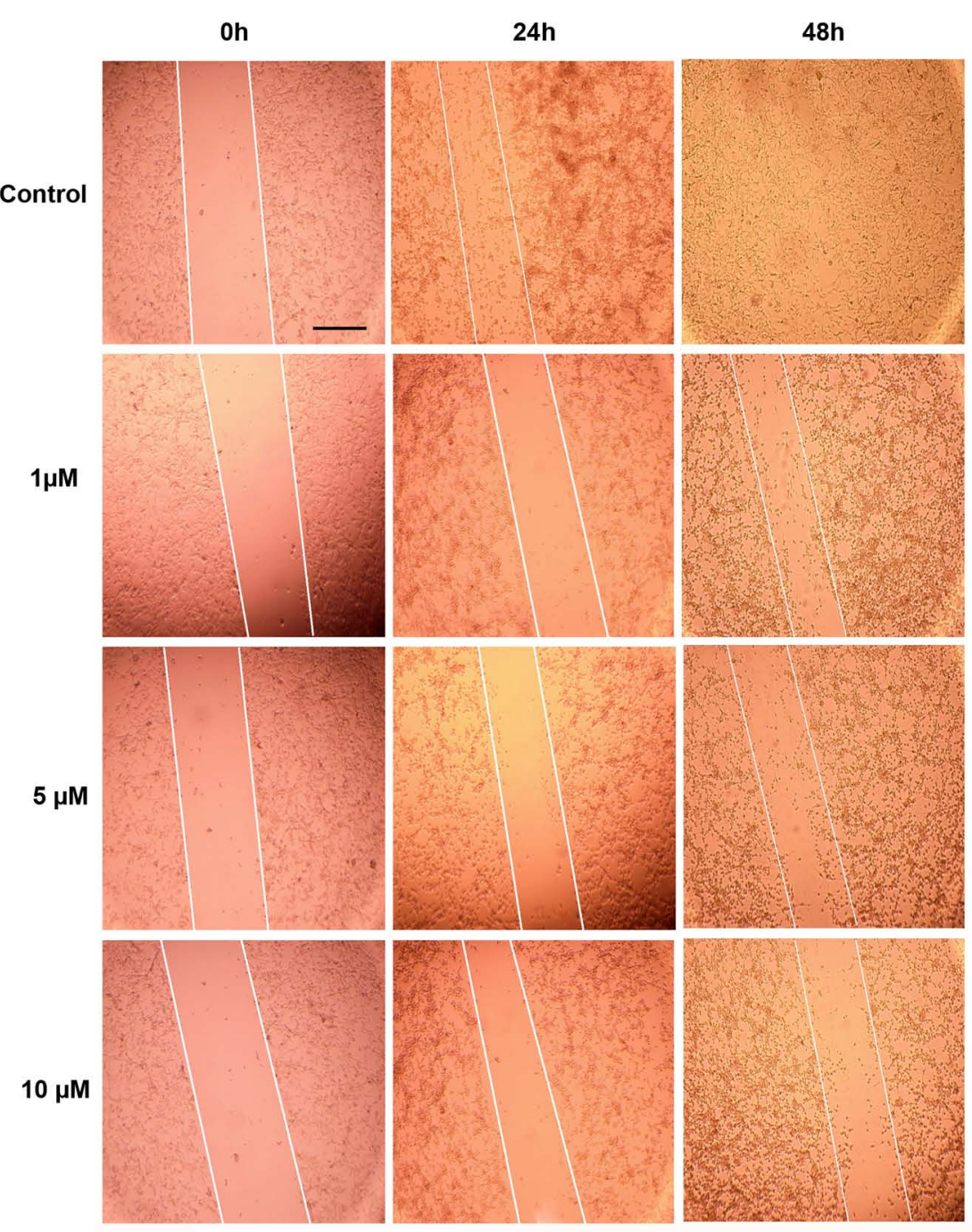

B

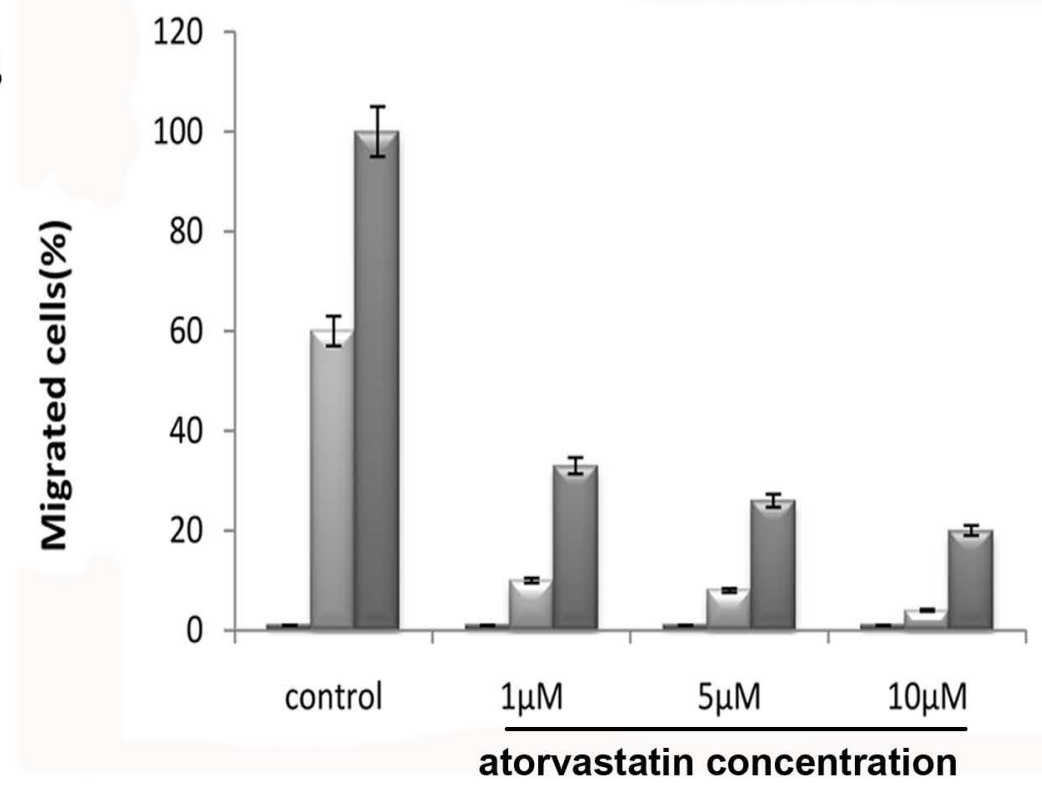

C

Control

$1 \mu \mathrm{M}$

$5 \mu \mathrm{M}$

$10 \mu \mathrm{M}$

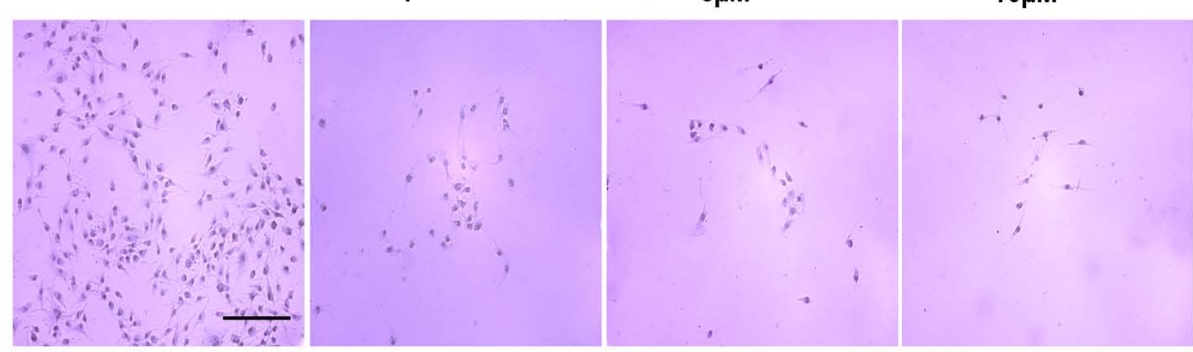

D

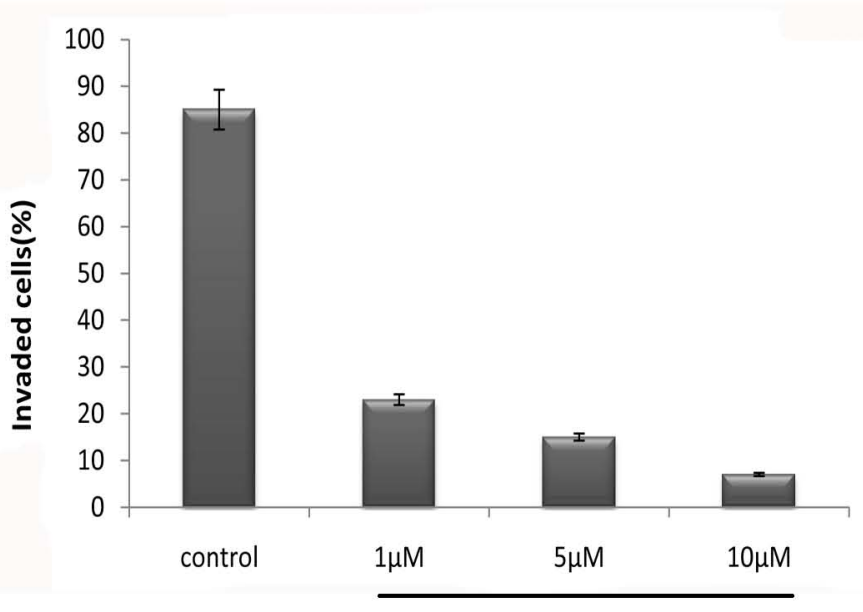

atorvastatin concentration 


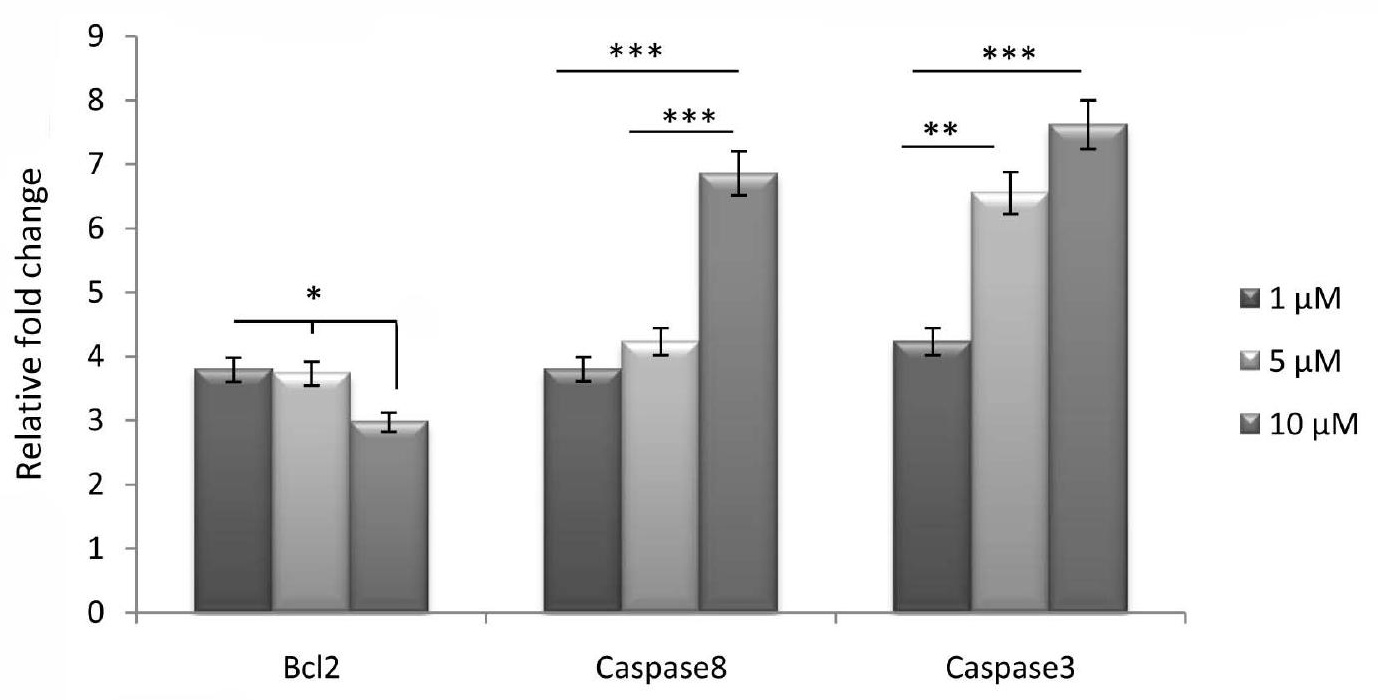

